\title{
Damage Assessment in Fibrous Composites Using Acoustic Emission
}

\author{
A.S. Paipetis and D.G. Aggelis \\ Department of Materials Science and Engineering, University of Ioannina,
}

Greece

\section{Introduction}

Acoustic Emission is by definition the phenomenon of stress or pressure wave generation during dynamic processes in materials. Failure of engineering materials is often preceded by audible events, as is well known in the case of timber, where the fibrous structure warns of its upcoming failure with the emission of characteristic sounds (Liptai et al. 1972). Early uses of acoustic emission analysis include elastic waves produced by earthquakes. Typical of the acoustic signature of the twinning is what is known as "tin cry", observed by tin smiths. Similar, the martensitic transformation in steel is known to produce clicking sounds. The seminal work by Joseph Kaiser initiated the research in acoustic emission as a result of irreversible energy dissipating processes occurring during the loading of materials and structures (Kaiser 1950). Within a decade, considerable research effort accompanied with extensive improvement in instrumentation led to the specification of the monitoring frequencies well above the audio range, in the area 0f 0.1 to $1 \mathrm{MHz}$ (Dunegan et al. 1964). Today, multi channel acquisition systems corroborated with computing power and advanced signal processing allow for the real time monitorin, location and damage identification in materials and structures (Caprino et al. 2011, Liu et al, 2010).

Acoustic emission (AE) has been used for monitoring of the structural condition and damage characterization for practically all kinds of materials and systems (Grosse and Ohtsu 2008, Mindess 2004, Prosser 2002). It exploits the transient elastic waves emitted during fracture incidences. It is the complete analogue of seismic activity recorded by seismographs, though in shorter range, which extends from a few $\mathrm{cm}$ in laboratory specimens to several $\mathrm{m}$ in real structures. The emitted waves are recorded by transducers that are fixed on the surface of the component under test. These are usually piezoelectric and transform the pressure felt on their surface to electric signals. The nature of the waves measured is identical to the waves utilized in another non destructive testing (NDT) technique, namely ultrasonic testing (UT). The fundamental difference between AE and UT is the absence of external wave excitation since the emissions originate from the cracking events within the material. Additionally, in AE the material should be stressed in order to produce active cracking events, unlike ultrasonics which do not require mechanical stress on the material. After the wave is transformed to an electric waveform it is normally preamplified and digitized in an acquisition board, see Fig. 1. 
The presence of cracks in the material alters the load at which irreversible deformation begins. Consequently, the acoustic emission pattern is altered. As a result, the AE technique can be used in laboratory conditions in order to monitor the fracture process of engineering materials and build an understanding on the damage behavior of materials under stress or other degradation factors (Carpinteri et al. 2010, Scholey et al. 2010, Philippidis et al. 1998, Ohtsu and Watanabe 2001, Kawasaki et al. 2010). It is also employed in real structures to monitor the cracking activity under service load (Shiotani et al. 1999, Shiotani et al. 2009, Aggelis et al. 2010a, Kurz et al. 2006), in order to estimate the structural integrity of rock mass related to landslide incidences (Shiotani 2006), of tanks and pressure vessels (Anastasopoulos et al. 2009, Anastasopoulos and Tsimogiannis 2004), while application in composite laminates is extensive (Anastasopoulos and Philippidis 1995, Prosser et al. 1995, Hamstad 1986, Katerelos et al. 2009).

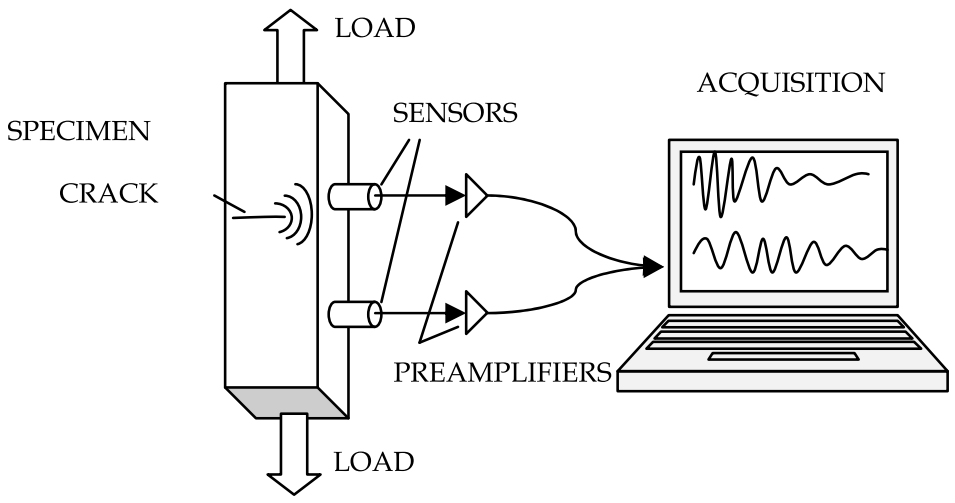

Fig. 1. Schematic representation of AE experiment.

Monitoring of AE behavior supplies information on several levels. One basic function is the characterization of the active crack density. Low AE activity is connected to low density of cracks, since cracking is the source of AE. The number or rate of recorded signals is a parameter of paramount importance and in many cases it is used among other parameters as a criterion for rejection or acceptance of components like pressure vessels and tanks [ASTM E 569, ASME 2005]. However, the total AE activity is not the only information supplied. The shape and content of each recorded waveform is the electric analogue of the elastic wave that impinged on the sensor, excluding the sensor's response. Additionally, this elastic wave depends on the motion of the crack tip during each incidence. Cracking events with high intensity, corresponding to large crack propagation rate, give rise to the emission of waves with high amplitude and energy. Additionally, the relative motion of the sides of the cracks, which defines the cracking mode, influences the shape of the AE waveform. Mode I, or tensile cracking is related to short waveforms with high frequency content, while mode II or cracks resembling shear correspond to longer waveforms and lower frequency content, see Fig. 2 (Ohtsu 2010). This has been shown in a number of studies concerning different kinds of materials like rock (Shiotani 2006), concrete (Ohno and Ohtsu 2010, Soulioti et al. 2009, Aggelis et al. 2011a), metals (Aggelis et al. 2011b) and composite laminates (Aggelis et al. 2010b). It originates from the different elastic wave modes (longitudinal and shear) that are emitted from the mode I excitation (opposing movement of the crack faces) and mode II (sliding movement) respectively (Aggelis et al. 2010c). 
In most of technical materials and structures fracture or deterioration process includes both basic cracking modes. Apart from basic cracking modes, it can be argued that every damage mechanism possess a different acoustic signature which is reflected on the pattern of the signal. In this respect, pattern recognition schemes may be employed to correlate distinct "damage entities" to signal attributes (Gutkin et al 2011). The abundance of information in the AE waveforms may allow for "black box" approaches where the observed damage process is correlated to signal attributes (Katerelos et al, 2009, Arumugam et al, 2011).) Alternatively, the knowledge on the effect of specific damage mechanisms on the $\mathrm{AE}$ waveform may provide the roadmap for the study of nucleation, evolution and interaction of different mechanisms (Aggelis et al. 2010b).

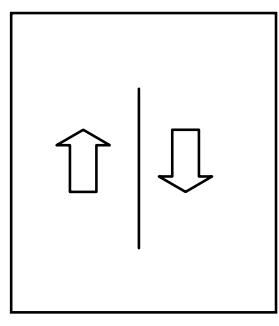

SHEAR

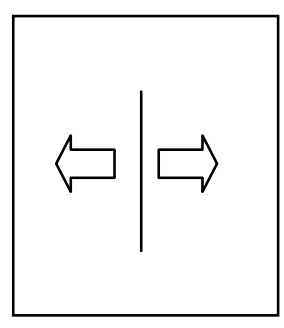

TENSILE

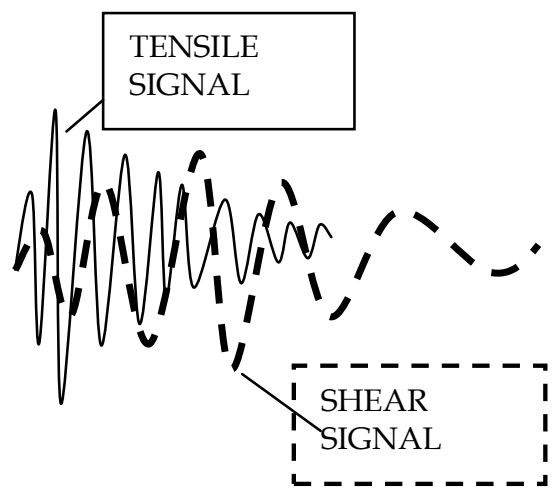

Fig. 2. Cracks modes and schematic representation of waveforms.

A typical AE waveform is depicted in Fig. 3 in detail with its main features. Amplitude, A, is the voltage exhibited by the highest peak of the waveform, which is normally correlated with the intensity of the crack propagation event. Other important parameters are the duration (DUR) and the rise time (RT) of the signal. DUR is defined as the time between the first and the last threshold crossing and is measured usually in $\mu \mathrm{s}$. RT indicates the delay between the onset of the signal (first threshold crossing) and the time of the maximum peak, again in $\mu$ s. A parameter that has extensively been used for characterization of the fracture mode mostly depends on the shape of the initial part of the waveform. The ratio of A over RT, which is the "rise angle" or "grade" (Anastassopoulos and Philippidis 1995, Philippidis et al. 1998) of the waveform, is recently utilized in the form of RA value (Ohtsu 2010, Ohtsu and Tomoda 2008, Soulioti et al. 2009, Aggelis et al. 2011a,b). This value is precisely the inverse of grade (rise time over the Amplitude measured in $\mu \mathrm{s} / \mathrm{V}$ ) (Ohno and Ohtsu 2010). The average frequency, AF is another essential parameter defined by the ratio of threshold crossings over the duration of the signal and is measured in $\mathrm{kHz}$. It is a rough but valuable indicator of the main frequency component and it has been proved sensitive to the fracture mode, with tensile cracking resulting in higher frequency than shear (Ohtsu 2010, Aggelis 2011). Additionally, AE energy (ENE) expresses the area under the rectified waveform envelope. Similarly to the amplitude, it expresses the severity of cracking since generation of a large crack could emit larger amount of energy than a small crack. 


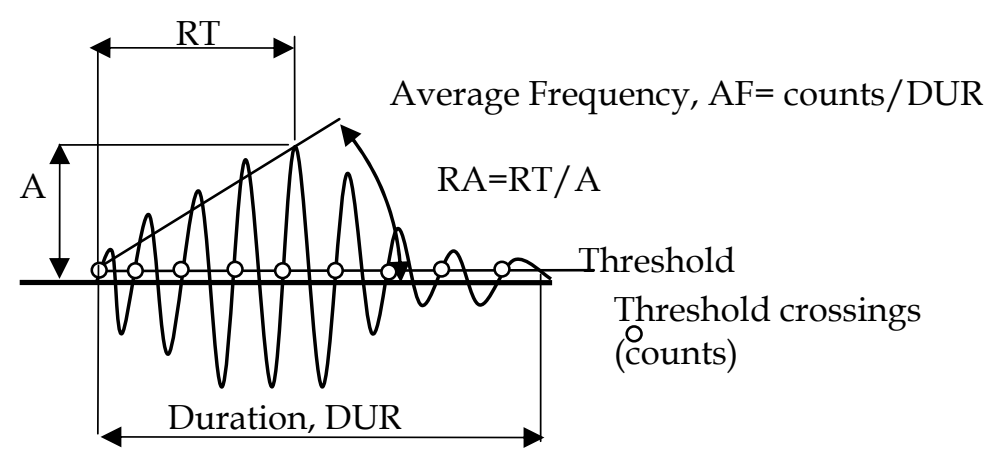

Fig. 3. Typical AE waveform

Fibrous composite materials are the ideal platform for correlating the acoustic signature of service induced damage to the degradation of the material or the structure. This is stemming from the fact that accumulating damage in composites varies in scale, dimension and is correlated to the service life of the material. Typical of the above behavior is damage initiation and propagation in multi axis reinforced composite laminates. In these systems, matrix cracking of the off-axis laminates is considered the primary mode of damage and is the result of complex combinations of thermal and mechanical loading. This damage mode is also referred to as "transverse" or "intra-laminar" cracking, as the cracks are oriented transversely to the loading direction and is the initial mode of damage to appear first in such composite systems. Transverse cracking has been studied extensively by several researchers over the last 25 years (Talreja 1994, Nairn and Hu 1994, Varna et al 1999, Nairn 2000), focussing mainly on cross-ply glass fibre reinforced polymer composite systems.

Failure in composite laminates typically starts by the creation of cracks of the off axis plies. The cracks in the off-axis layers usually propagate along the whole width of the specimens parallel to the fibres direction of the corresponding off-axis laminae. The crack density which is a parameter that characterises these systems and is defined as the number of cracks normalised by the length of the specimen depends on many parameters. Load level, layer orientation with respect to the load direction, temperature change, number of fatigue cycles, laminate stacking sequence, ply thickness and material fracture toughness are the most important parameters that dominate the crack density. Damage development in the form of transverse matrix cracking reduces the stress-bearing ability of individual layers resulting in the deterioration of the laminate's thermo-elastic properties.

In the simplest case of cross ply laminates where reinforcement is at $0^{\circ}$ and $90{ }^{\circ}$ to the loading axis, the crack at the $90^{\circ}$ ply or the transverse crack creates a shear discontinutity at the interface between the $0^{\circ}$ and the $90^{\circ}$ ply. The crack may either be deflected at the interface creating a delamination or propagate within the $0^{\circ} \mathrm{ply}$. This is well known to be a function of the interlaminar shear strength the interface. With increasing load, transverse cracking accumulates and may reach a saturation stage, when the interlaminar shear strength is reach and no further load may be transferred to the neighbouring longitudinal ply. At the same time, longitudinal fiber failure occurs due to the stress concentration at the crack tip which is more pronounced with increasing interlaminar shear strength. 
Cumulative failure of the longitudinal fibre is the primary failure mechanism in such systems. The failure process is depicted in Fig. 4.

Due to the succession of the different damage mechanisms, it is realized that real-time characterization of the cracking mode would supply information on the actual fracturing stage, enabling predictions on remaining life of the composite. This is a subject that concentrates strong efforts in the engineering community for decades. The results are not always successful since many factors hinder the reliable classification of the signals. Briefly these include the experimental details like the frequency response of the sensors, the specimen geometry which is not fixed, as well as the effect of propagation which may seriously alter the content of an elastic wave through an inhomogeneous and dispersive medium. It is however shown that in a variety of cases, different damage entities may be readily classified according to their acoustic signature (Katerelos et al 2009, Kostopoulos et al 2007a, Kostopoulos et al 2007b.)

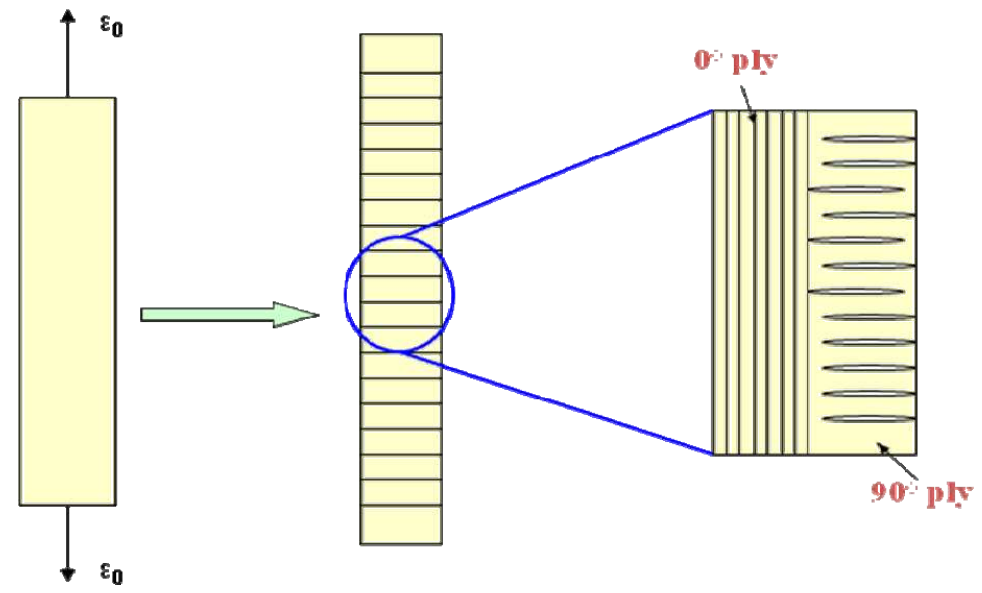

Fig. 4. Failure of cross ply laminates

This chapter describes the basics of an AE monitoring study of cross-ply laminates, emphasizing on the features that prove sensitive to the damage mechanism in small scale laboratory conditions. These composite material systems are excellent for crack monitoring which is performed via the matching of the refractive index of the fibres and the epoxy resin. In this way, they can be made transparent and thus, the optical observation of the crack development is feasible.

\section{Experimental methods}

The cross-ply laminates were fabricated by hand layup with a sequence $\left[0^{\circ}{ }_{4} / 90^{\circ}{ }_{4}\right]_{\mathrm{s}}$, resulting in a number of 16 plies with total specimen thickness of $2 \mathrm{~mm}$. The UD $220 \mathrm{~g} / \mathrm{m} 2$ (Aero) unidirectional glass fibre fabric was impregnated using the HT2 epoxy resin/hardener matrix system (mixing ratio 100:48) manufactured by R\&G Faserverbundwerkstoffe $\mathrm{GmbH}$ Composite Technology. A 250×250 mm2 laminate was manufactured and was allowed to cure for $24 \mathrm{~h}$ at room temperature. Tensile specimens were subsequently cut according to 
the ASTM D3039 standard, at a width of $20 \mathrm{~mm}$ each. The matching of the refractive index of the glass fibres and the epoxy matrix resulted in the manufacturing of transparent laminates which enabled the optical observation of the failure modes of the composite laminate.

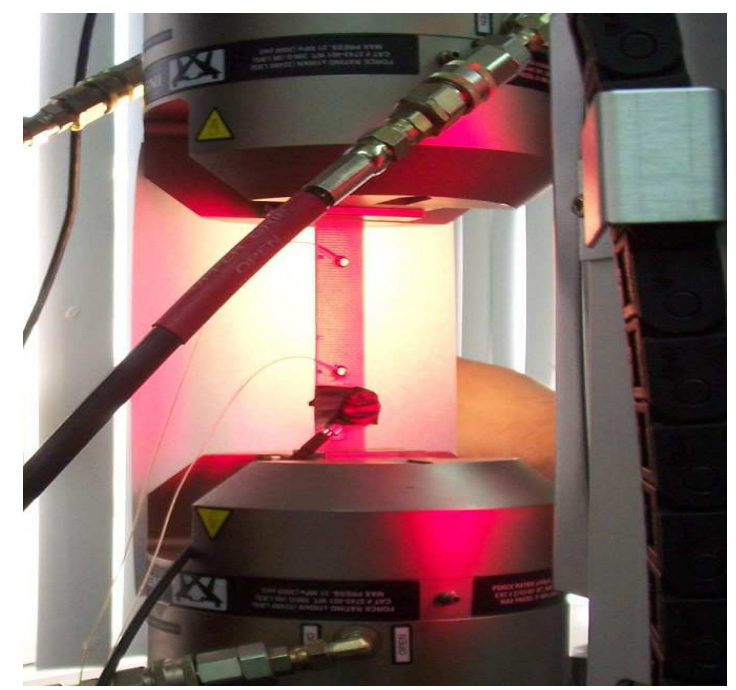

Fig. 5. Experimental set-up

The tensile specimens were loaded in load controlled tension, in a step loading mode. The loading spectrum was a saw-tooth spectrum formed from a sequence of triangular loading/unloading steps. A rate $5 \mathrm{kN} / \mathrm{min}$ was employed for both loading and unloading. The maximum load was incremented by $4 \mathrm{kN}$ at each consecutive step. The step loading continued until the tensile failure of the specimen. All tensile tests were performed using an Instron Universal Testing Machine equipped with hydraulic gripping system, under load control, at controlled environmental conditions of $25{ }^{\circ} \mathrm{C}$ and $70 \%$ relative humidity (ASTM D3039).

For the AE monitoring, two wide band AE sensors (Pico, Physical Acoustics Corp., PAC) were attached on the same side of the specimen), as shown in Fig. 5. Electron wax was applied between the sensors and the specimen to enhance acoustic coupling, while it offered the necessary support to the sensors during the experiment. Due to the specific sensors sensitivity to frequencies from $50 \mathrm{kHz}$ up to approximately $800 \mathrm{kHz}$, they can capture a wide range of different sources. The distance between the two receivers was $70 \mathrm{~mm}$. The pre-amplifier gain was set to $40 \mathrm{~dB}$. After performing a pilot test, the threshold was also set to $40 \mathrm{~dB}$ in order to avoid the possibility of electronic/environmental noise. The signals were recorded in a twochannel monitoring board PCI-2, PAC with a sampling rate of $5 \mathrm{MHz}$.

\section{Results and discussion}

The most basic parameter of an AE monitoring is the number of incoming signals, which as aforementioned in many cases of standardized monitoring serves as a criterion for structural 
integrity characterization. Usually the number of hits increases with load, due to the increase of crack propagation rate as the load increases. This behavior is seen in Fig. 6 concerning the cross-ply laminates subjected to the incremental step loading for the last 5 steps to failure. For each successive loading step, the cumulative AE activity increases considerably. The first cycle produced a few tens of hits, while during the last full cycle (\#6) more than 20000 hits were recorded. This increase is reasonable due to the fact that as the load increases, apart from the matrix cracking that becomes extensive, numerous delaminations occur which were not active at the first loading steps. Additionally, the rate of cracking is more rapid and the fracture events happen progressively faster emitting the corresponding signals in rates of hundreds/s. It is mentioned that the number of cumulative $\mathrm{AE}$ activity was very repeatable for all specimens and therefore it can act as an indication of the forthcoming failure. However, this is limited to the cases where exactly the same conditions apply, which refer to material, specimen geometry, sensor type and separation distance, as well as specialized user-defined hardware settings concerning acquisition.

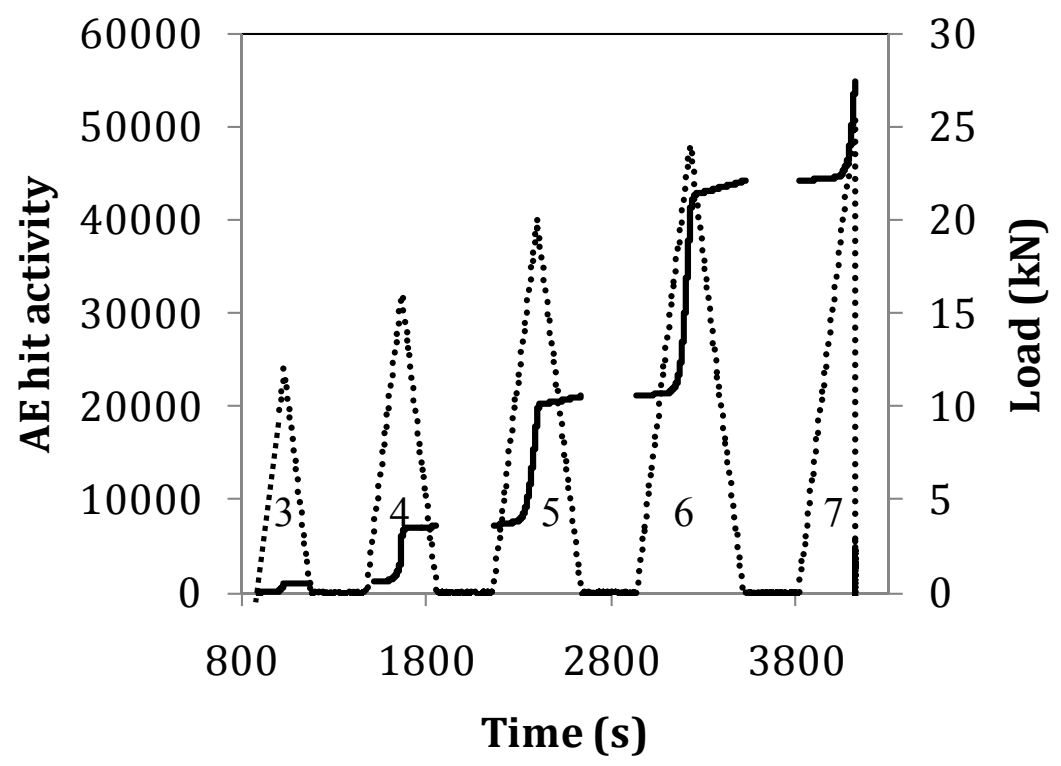

Fig. 6. Typical cumulative AE activity and loading history.

The number of accumulated hits correlates well with the maximum load of each cycle, as can be seen in Fig. 7 following an exponential growth function. The data come from different specimens showing the potential to characterize the sustained load by the number of AE signals under controlled conditions.

The total number of data originates from any different damage mechanism, which may include matrix cracking, delaminations and finally longitudinal fiber breakage. Although it is not straightforward to separate the different populations of data according to their origin, still correlations of this kind are of paramount importance as they enable estimations on the sustained load based on parameters measured in a non invasive way. 


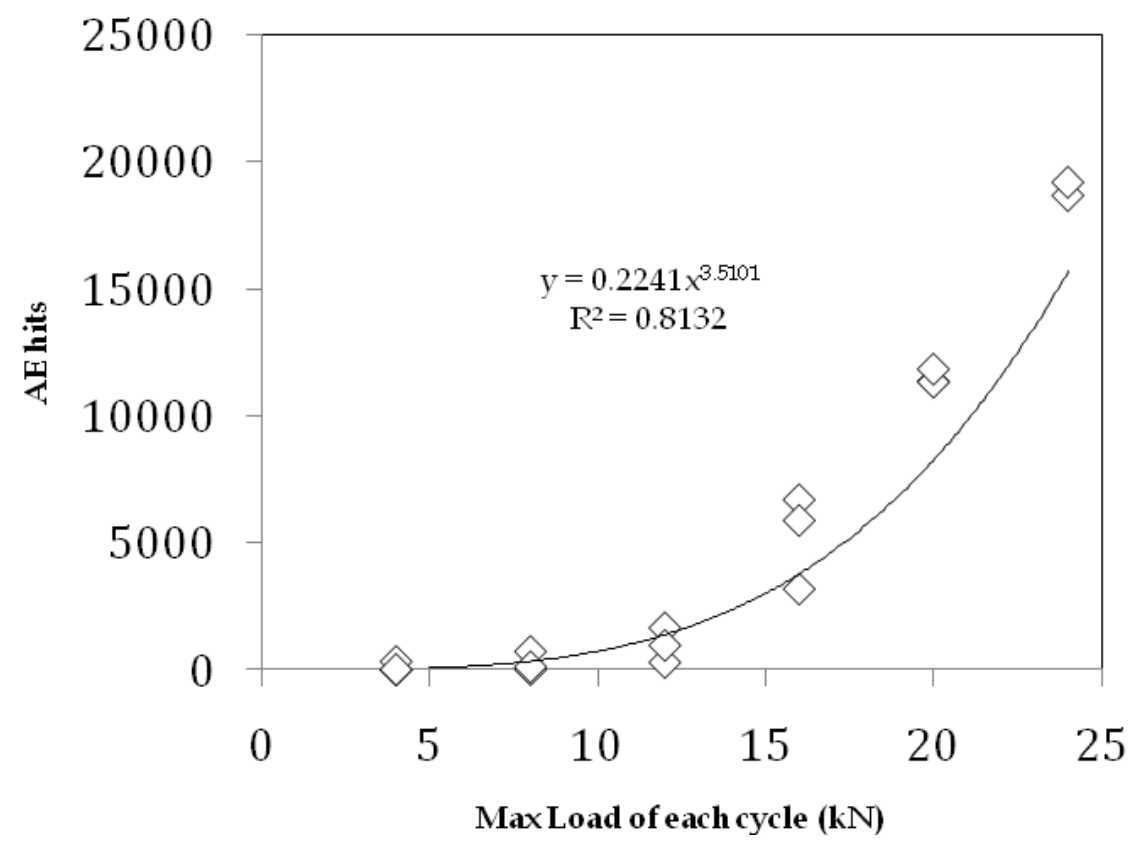

Fig. 7. Correlation between AE hits and maximum sustained load.

Though the general sequence of activation of the fracture mechanisms is known, the degree of overlapping between them cannot be confirmed by the number of the acquired hits. The task of characterization of the signals based on the damage mode can be assisted by the study of the qualitative parameters of the $\mathrm{AE}$ waveforms. As aforementioned, the shape and content of the signal strongly depends on the motion of the crack sides and therefore, on the damage mode. Waveform parameters like the RA have been used for characterization of source in different materials, as mentioned above. Actually, the RA value experiences great shifts during the specific loading protocol, as seen in Fig. 8. The RA level increases for each successive step. For the initial low level steps RA is limited below $10 \mathrm{~ms} / \mathrm{V}$, while for increasing loading step, the RA continuously rises. At the moment of failure, several signals exhibit RA close to or higher than $200 \mathrm{~ms} / \mathrm{V}$. This is characteristic of the gradual shift of the damage mechanism from matrix cracking to delaminations. It is reasonable that the low loads of the initial steps are responsible mostly for matrix cracking while delaminations occur at the highest load levels. The information of Fig. 8 is very informative and indicative of the shift in the damage mode. However, treatment of data in acoustic emission is mainly statistical, since the number of signals can easily reach several thousands or more and therefore, it is more meaningful to discuss on the trends and not on single signals. Therefore, Fig. 9 depicts the RA value as the moving average of the recent 200 hits in order to clear the trend from the cloud of points. Initially, the average RA is contained below $1 \mathrm{~ms} / \mathrm{V}$, while for each successive step it exhibits a considerable increase, reaching approximately $10 \mathrm{~ms} / \mathrm{V}$ just before the moment of ultimate failure. Apart from the increase for each step, it is interesting to note that the RA line increases within each loading step until the load reaches the maximum value. RA starts from a value around $0.5 \mathrm{~ms} / \mathrm{V}$ and gradually reaches a peak 
value at the moment of maximum load. Immediately after the load starts to decrease according to the loading protocol, the RA almost instantly drops and remains low until the load starts to increase at the next step. This is characteristic of the shift of damage mechanisms even within each step.

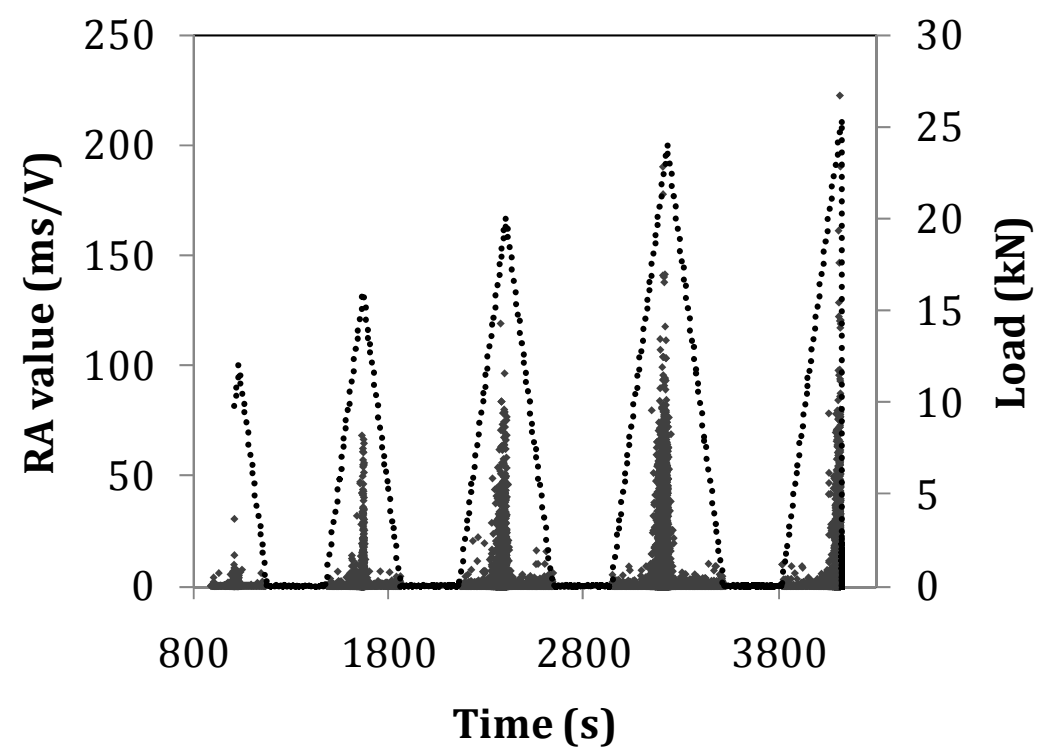

Fig. 8. RA value and Load time history.

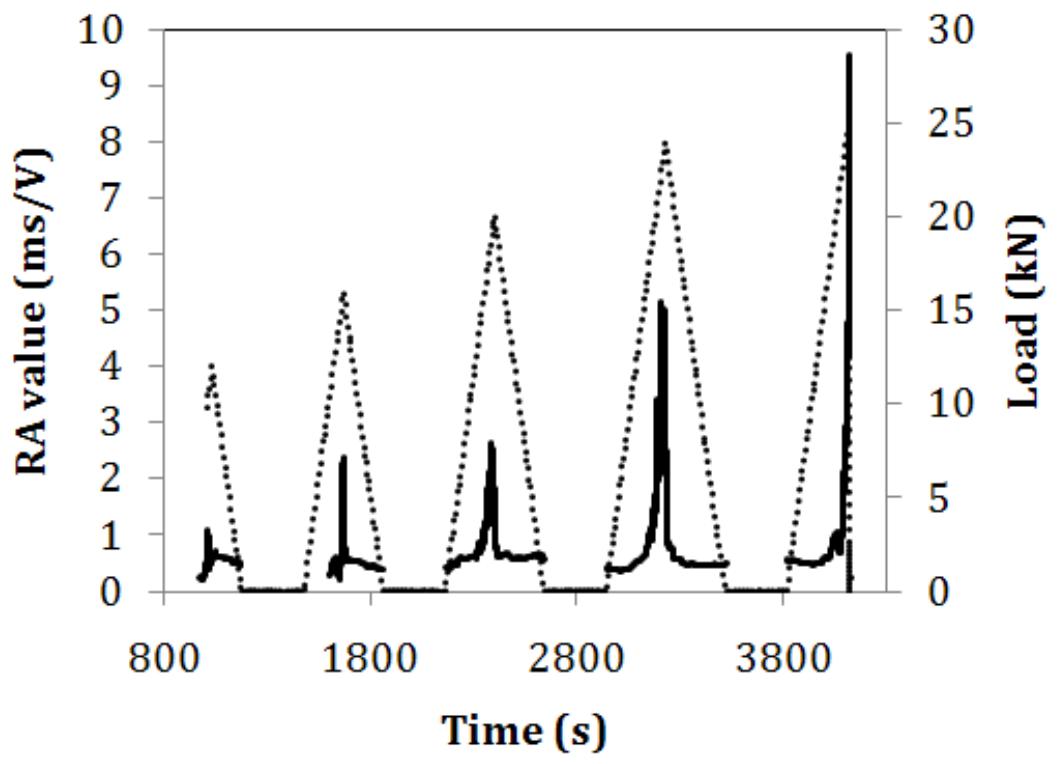

Fig. 9. Moving average of RA value and Load time history. 
Averaging the RA of all the AE signals for each successive step results in a very strong correlation as seen in Fig. 10a. As the maximum load is increasing for each step, the RA was shifting to higher values (see Fig. 10a). This increase is considered indicative of the gradually increasing population of delamination events relatively to the matrix cracking ones. Each successive step exhibits higher RA values and at the final step, while the material is approaching final failure, RA exhibits its maximum average value of almost $3 \mathrm{~ms} / \mathrm{V}$ (see Fig. 10a). As can be seen, the load and the mean RA strongly correlate.

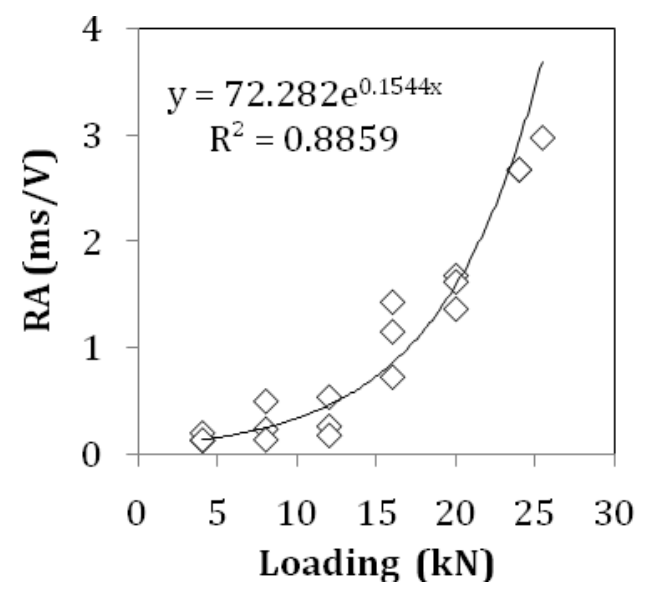

(a)

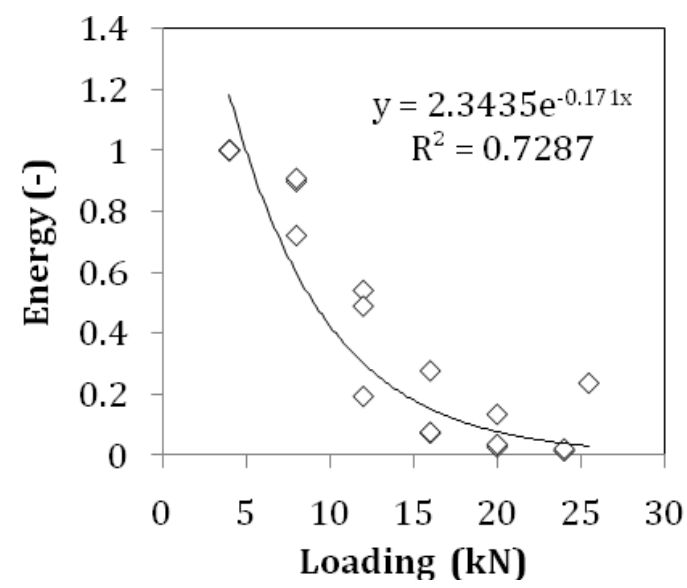

(b)

Fig. 10. (a) RA and (b) average energy vs. maximum load of each cycle

Several other correlations between AE parameters and load can be observed. Indicatively, Fig. $10 \mathrm{~b}$ shows the development of the average energy of the AE signals according to the maximum load of each cycle. The values are normalized to the energy of the first cycle. It is evident that as loading (and deterioration of the material is accumulated) the average 
energy shifts to lower values. This may initially seem contradictive to the increasing crack propagation rate. However, it should be considered that the number of AE signals are continuously increasing with load. This implies that the fracture energy is distributed to many more events, reducing their average intensity. Summarizing, the load history and consequently all induced damage mechanisms, leave a distinct signature on the acoustic emission behavior both on the cumulative activity as well as the qualitative characteristics of the acquired waveforms. Monitoring of the AE parameters provides valuable information in respect to the load induced damage of the composite and provide early warning of the forthcoming failure.

It is interesting to note that this kind of classification approach based on RA has been applied in different materials. RA value exhibits an explosive increase when fiber pull-out events result after extensive matrix cracking (Soulioti et al. 2009, Aggelis et al. 2011a,c). The same trend has been seen in concrete containing polymer fibers, as studied by the inverse of RA, namely "grade" of the waveform (Aggelis et al. 2009). Additionally, these parameters have been used for characterization of the development of corrosion cracking (Ohtsu and Tomoda 2008, Kawasaki et al. 2010) as well as fracture of reinforced concrete bars (Ohno and Ohtsu, 2010), while they have been shown effective in rock during landslides (Shiotani, 2006).

In an alternative approach, the correlation of independently observed damage mechanisms may be correlated to the attributes of the recorded acoustic waveforms. Pattern recognition algorithms were utilised to classify and associate the acquired AE signals to the material's damage mechanisms during the monotonic loading of the aforementioned cross ply laminates. As the laminates were transparent, the optical identification and correlation of the transverse cracking to the acoustic activity of the specific damage mechanism enabled the identification of two additional damage mechanisms. These continued to be active until the failure of the specimens. Fig. 11 presents a typical load time curve recorded during the monotonic tensile loading of the composite together with the crack density. This was obtained by taking snapshots during loading at specific intervals. The photographs allowed for the measurement of the cracks as they appeared as lines in the transparent laminates (Katerelos et al 2009).

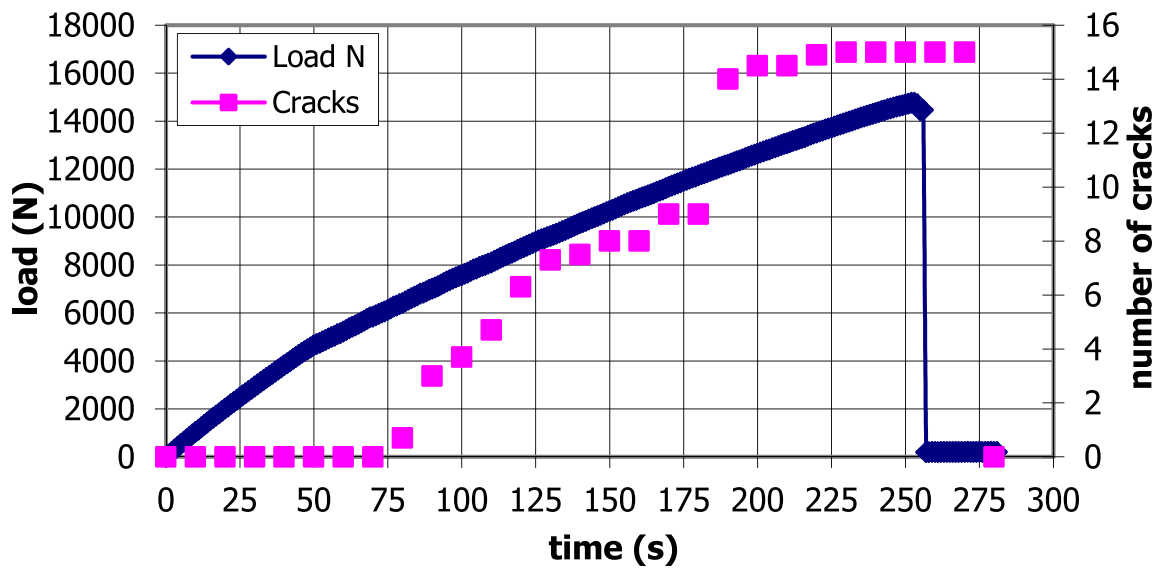

Fig. 11. Load and number of cracks measured in the gauge length for a typical tensile experiment. 
Employing pattern recognition algorithms based on the various descriptors from the acquired waveforms, the appropriate clustering that corresponds to the observed damage mechanisms may be attained. Fig. 12 presents the resulting clustering in three classes employing a combination of Maxmin distance and Isodata algorithms (Katerelos 2009). The figure represents a $2 \mathrm{D}$ projection of the classes that are completely separated in the 4th dimensional space. The descriptors employed for the specific clustering were amplitude, rise angle, initiation frequency and mechanical load. Cluster validity criteria such as $R$ and $\tau$ criteria (Fukunaga 1990, Tou and Gonzales 1974) were applied to confirm the successful separation of the AE population.

Concurrent observation of the optical evolution of damage allowed for the correlation of the separate classes to distinct failure mechanisms. As was observed all acoustic activity initiated shortly before the appearance of transverse cracks. Class 1 was active until fracture. Class 2 became audible when the characteristic knee at the stress curve was recorded at approximately $50 \mathrm{~s}$ (Fig. 11) and went silent after the saturation of transverse cracking. Class 3 was audible shortly before the silencing of class 2, and was notably higher in terms of energy content (Katerelos 2009). As is obvious, class 2 may readily be attributed to transverse cracking, class 3 is the primary failure mechanism, or the longitudinal fibre breaking. Class 1 is related to all secondary energy dissipating mechanisms such as interfacial sliding and interfacial bond failure. In this way, the identification of all major mechanisms that precede and accumulate to lead to failure may be monitored and provide information about the structural integrity of the material or the structure.

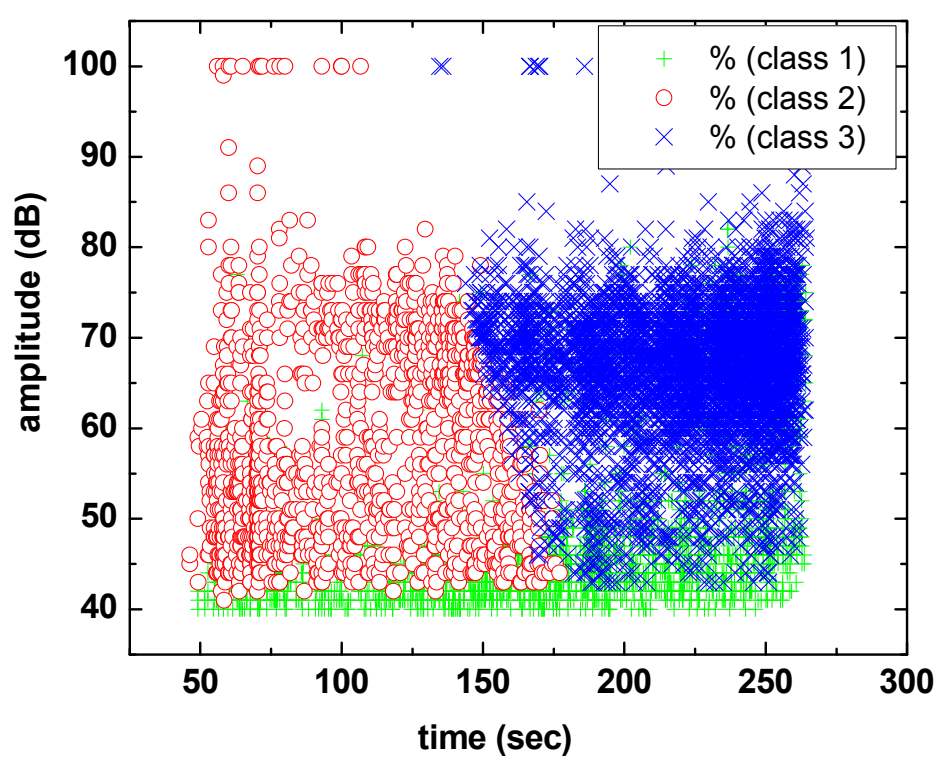

Fig. 12. Separation of resulted classes in 2-D projection. 


\section{Conclusions}

The discussion in the chapter intends to shed light in the fracture process of cross-ply laminates enabling the characterization of the damage stage reliably using simple parameters collected in a non destructive fashion utilizing acoustic emission technique. It is stressed that in laboratory conditions mechanical parameters such as load and displacement are measured simultaneously with AE data. Therefore, any macro-cracks can be easily detected, even by visual observation. The main benefit of $\mathrm{AE}$ test and analysis results from the fact that specific AE signatures are closely related to damage mechanisms, which is crucial for real size structures. In an actual structure a crack of similar size will not result in visually detectable deformation. Therefore, in order to detect and identify damage in the early stages AE monitoring would be very effective. Different AE parameters like the energy and RA exhibit strong sensitivity to the fracture mode (tensile micro-cracking and delaminations). Average AE energy near ultimate fracture decreases by more than $90 \%$ compared to the initial small scale fracture, while RA increases by at least 20 times. These parameters prove very sensitive to the damage mode and deterioration and therefore, can be used for estimation of the remaining life of the component. The abundance of information in the acoustic waveform is also indicative of the fact that clustering algorithms based on the signal descriptors may be directly attributed to distinct failure mechanisms and yield information about the life stage of the interrogated material.

Studies in the field should continue aiming at the establishment of specific and simple criteria for damage qualification, as well as in the application to real size structures, since propagation through thin plates is dispersive and special care should be given for the interpretation of data collected after long distances.

\section{References}

Aggelis D. G., 2011. Classification of cracking mode in concrete by acoustic emission parameters, Mechanics Research Communications 38, 153-157

Aggelis D. G., Kordatos E. Z., Matikas T. E., 2011b. Acoustic emission for fatigue damage characterization in metal plates, Mechanics Research Communications 38, 106-110.

Aggelis, D. G., Shiotani T., Terazawa, M. 2010a.Assessment of construction joint effect in full-scale concrete beams by acoustic emission activity. Journal of Engineering Mechanics, 136(7), 906-912.

Aggelis, D. G., Soulioti, D. V., Barkoula, N. M., Paipetis, A. S., Matikas, T. E. 2011c. Influence of fiber chemical coating on the acoustic emission behavior of steel fiber reinforced concrete, Cement and Concrete Composites, 34 (2012) 62-67

Aggelis, D.G., Barkoula, N.M., Matikas, T.E., Paipetis, A.S. 2010b. Acoustic emission monitoring of degradation of cross ply laminates. J Acoust Soc Am., 127(6), EL246251.

Aggelis, D.G., Matikas, T.E., Shiotani, T. 2010c. Advanced acoustic techniques for health monitoring of concrete structures. In "The Song's handbook of concrete durability", Kim SH, Ann KY eds, pp. 331-378, Middleton Publishing Inc.

Aggelis, D.G., Shiotani, T., Momoki, S., Hirama, A. Acoustic emission and ultrasound for damage characterization of concrete elements. ACI Materials J. 2009, 106(6), 509514. 
Aggelis, D.G., Soulioti, D.V., Sapouridis, N., Barkoula, N.M., Paipetis, A.S., Matikas, T.E. 2011a. Acoustic emission characterization of the fracture process in fibre reinforced concrete, Construction and Building Materials 25 4126-4131.

Anastasopoulos A, Tsimogiannis A. 2004. Evaluation of acoustic emission signals during monitoring of thick-wall vessels operating at elevated temperatures. JAE. 22:59-70.

Anastasopoulos, A., Kourousis, D., Botten, S., Wang, G., 2009. Acoustic emission monitoring for detecting structural defects in vessels and offshore structures, Ships and Offshore Structures, 4(4), 363 - 372.

Anastassopoulos, A., and Philippidis, T. P. 1995. Clustering methodology for evaluation of acoustic emission from composites, J. Acoust. Emiss., 13, 11-22.

Arumugam, J., Kumar, C.S., Santulli, C., Sarasini, F., Stanley, A.J., 2011. A global method for the identification of failure modes in fiberglass using acoustic emission Journal of Testing and Evaluation, 39 (5).

ASME, Section V, Article 12. 2005. Acoustic emission examination of metallic vessels during pressure testing. New York: ASME.

ASTM E 569. 2002. Standard practice for acoustic emission monitoring of structures during controlled stimulation.West Conshohocken, PA: ASTM International.

Caprino, G., Lopresto, V., Leone, C., Papa, I., 2011. Acoustic emission source location in unidirectional carbon-fiber-reinforced plastic plates with virtually trained artificial neural networks, Journal of Applied Polymer Science, 122 (6), 3506-3513.

Carpinteri, A., Cardone, F., Lacidogna, G.,. Energy Emissions from Failure Phenomena:Mechanical, Electromagnetic, Nuclear. Experimental Mechanics 2010, 50, 1235-1243.

Dunegan, H. L., Harris, D. O., and Tatro, C. A., "Acoustic Emission research", Report UCID4868, Lawrence Radiation Laboratioy, Livermore, California, 1964.

Fukunaga, K.., Introduction to statistical pattern recognition, 2nd English ed. San Antonio, CA, USA: Academic Press; 1990.

Grosse, C. U., Ohtsu, M. 2008. Acoustic Emission Testing, Springer, Heidelberg.

Gutkin, R., Green, C.J., Vangrattanachai, S., Pinho, S.T., Robinson, P., Curtis, P.T. 2011. On acoustic emission for failure investigation in CFRP: Pattern recognition and peak frequency analyses, Mechanical Systems and Signal Processing, 25 (4), 1393-1407.

Hamstad MA. 1986. A review: acoustic emission, a tool for composite materials studies. Exp Mech;26(1):7-13.

Kaiser, J., Ph. D Thesis, 1950.

Katerelos, D. G., Paipetis, A. S., Loutas, T., Sotiriadis, G., Kostopoulos, V., and Orgin, S. L., 2009. "In situ damage monitoring of cross-ply laminates using acoustic emission," Plast. Rubber Compos. 38, 229-234.

Kawasaki, Y., Tomoda, Y., Ohtsu, M. AE monitoring of corrosion process in cyclic wet-dry test. Construction and Building Materials 2010, 24, 2353-2357

Kostopoulos, V., Loutas, T., Dassios, K. 2007a. Fracture behavior and damage mechanisms identification of $\mathrm{SiC} /$ glass ceramic composites using $\mathrm{AE}$ monitoring, Composites Science and Technology, 67 (7-8), 1740-1746.

Kostopoulos, V., Tsotra, P., Karapappas, P., Tsantzalis, S., Vavouliotis, A., Loutas, T.H., Paipetis, A., Friedrich, K., Tanimoto, T., 2007b. Mode I interlaminar fracture of CNF or/and PZT doped CFRPs via acoustic emission monitoring, Composites Science and Technology, 67 (5), 822-828. 
Kurz, J.H., Finck, F., Grosse, C.U., and Reinhardt, H.W. 2006. Stress drop and stress redistribution in concrete quantified over time by the b-value analysis. Structural Health Monitoring, 5, 69-81.

Liptai, R. G., Harris, D. O., and Tatro, C, A., "An Introduction to Acoustic Emission", Acoustic Emission, ASTM STP505, American society for testing and Materials, 1972, pp.3-10.

Liu, Z., Pang, B., Tang, Q., 2010. Acoustic emission source location in laminated plates based on virtual wave front, Yadian Yu Shengguang/Piezoelectrics and Acoustooptics, 32 (3), 493-497.

Mindess S., 2004. Acoustic Emission Methods. In CRC Handbook of Nondestructive Testing of Concrete, Editors Malhotra V.M., Carino N. J., CRC, Boca Raton, FL.

Nairn, J. "Matrix microcracking in composites". In: Kelly, A., Zweben, C., Talreja, R. and Manson, J. - A., editors. Polymer matrix composites. Comprehensive composite materials, vol. 2. Amsterdam: Elsevier; 2000.

Nairn, J. and Hu, S. "Matrix microcracking". In: Pipes R.B., Talreja R, editors. Damage mechanics of composite materials. Composite materials series, vol. 9. Amsterdam: Elsevier; 1994.

Ohno, K., Ohtsu, M. 2010. Crack classification in concrete based on acoustic emission. Construction and Building Materials, 24(12), 2339-2346.

Ohtsu M., Recommendation of RILEM TC 212-ACD 2010. Acoustic emission and related NDE techniques for crack detection and damage evaluation in concrete: Test method for classification of active cracks in concrete structures by acoustic emission, Materials and Structures, 43(9), 1187-1189.

Ohtsu, M, Watanabe H. 2001. Quantitative damage estimation of concrete by acoustic emission. Constr Build Mater, 15, 217-24.

Ohtsu, M., Tomoda, Y. 2008. Phenomenological model of corrosion process in reinforced concrete identified by acoustic emission. ACI Mater J. 105(2), 194-199.

Philippidis, T.P., Nikolaidis, V.N., Anastassopoulos, A.A. 1998. Damage characterization of carbon/carbon laminates using neural network techniques on AE signals. NDT\&E Int., 31(5), 329-340.

Prosser WH, Jackson KE, Kellas S, Smith BT, McKeon J, Friedman A. 1995. Advanced, waveform based acoustic emission detection of matrix cracking in composites. Mater Eval;53(9):1052-8.

Prosser, W. H. 2002. Acoustic Emission. In P. J. Shull (ed.) Nondestructive evaluation, theory, techniques and applications, pp.369-444, Taylor and Francis, Boca Raton

Rose, J. L., “Ultrasonic waves in solid media”, Camridge University Press, Cambridge, 2004.

Scholey, J. J., Wilcox, P. D., Wisnom, M. R., Friswell, M. I. Quantitative experimental measurements of matrix cracking and delamination using acoustic emission, Composites: Part A 2010, 41, 612-623.

Shiotani, T., 2006. Evaluation of long-term stability for rock slope by means of acoustic emission technique, NDT\&E Int, 39(3), 217-228.

Shiotani, T., Aggelis D. G., Makishima O., 2009. Global monitoring of large concrete structures using acoustic emission and ultrasonic techniques. Journal of Bridge Engineering-ASCE, 14(3), 188-192.

Shiotani, T., Shigeishi, M., and Ohtsu, M. 1999. Acoustic emission characteristics of concrete piles. Constr. Build. Mater., 13, 73-85. 
Soulioti, D., Barkoula, N.M., Paipetis, A., Matikas, T.E., Shiotani, T., Aggelis D.G. 2009. Acoustic emission behavior of steel fibre reinforced concrete under bending. Construction and Building Materials 23, 3532-3536.

Talreja, R. "Damage characterization by internal variables". In: Pipes, R.B. and Talreja, R., editors. Damage mechanics of composite materials. Composite materials series, vol. 9. Amsterdam: Elsevier; 1994.

Tou, J.T., and Gonzales, R.C., Pattern recognition principles. Reading, MA:Addison-Wesley; 1974.

Varna, J., Joffe, R., Akshantala, N.V. and Talreja, R., 1999. Damage in composite laminates with off-axis plies, Composites Science \& Technology ,; 59(14), 2139-2147. 


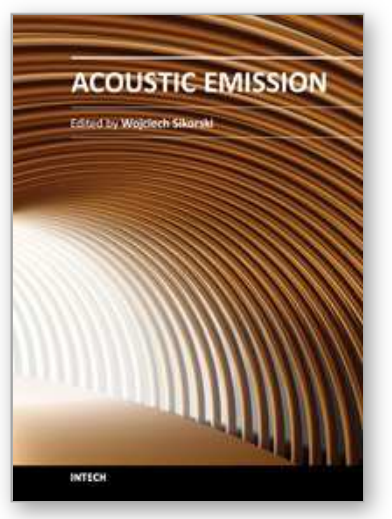

\author{
Acoustic Emission \\ Edited by Dr. Wojciech Sikorski
}

ISBN 978-953-51-0056-0

Hard cover, 398 pages

Publisher InTech

Published online 02, March, 2012

Published in print edition March, 2012

Acoustic emission (AE) is one of the most important non-destructive testing (NDT) methods for materials, constructions and machines. Acoustic emission is defined as the transient elastic energy that is spontaneously released when materials undergo deformation, fracture, or both. This interdisciplinary book consists of 17 chapters, which widely discuss the most important applications of AE method as machinery and civil structures condition assessment, fatigue and fracture materials research, detection of material defects and deformations, diagnostics of cutting tools and machine cutting process, monitoring of stress and ageing in materials, research, chemical reactions and phase transitions research, and earthquake prediction.

\title{
How to reference
}

In order to correctly reference this scholarly work, feel free to copy and paste the following:

A.S. Paipetis and D.G. Aggelis (2012). Damage Assessment in Fibrous Composites Using Acoustic Emission, Acoustic Emission, Dr. Wojciech Sikorski (Ed.), ISBN: 978-953-51-0056-0, InTech, Available from: http://www.intechopen.com/books/acoustic-emission/damage-assessment-in-fibrous-composites-usingacoustic-emission

\section{INTECH}

open science | open minds

\section{InTech Europe}

University Campus STeP Ri Slavka Krautzeka 83/A 51000 Rijeka, Croatia Phone: +385 (51) 770447

Fax: +385 (51) 686166 www.intechopen.com

\section{InTech China}

Unit 405, Office Block, Hotel Equatorial Shanghai No.65, Yan An Road (West), Shanghai, 200040, China 中国上海市延安西路65号上海国际贵都大饭店办公楼405单元 Phone: +86-21-62489820

Fax: $+86-21-62489821$ 
(C) 2012 The Author(s). Licensee IntechOpen. This is an open access article distributed under the terms of the Creative Commons Attribution 3.0 License, which permits unrestricted use, distribution, and reproduction in any medium, provided the original work is properly cited. 